\title{
Correction to: Mountains and Urbanism in Kandy
}

Wasana De Silva

\section{Correction to: \\ Chapter "Mountains and Urbanism in Kandy" in: H. Bougdah et al. (eds.), Urban and Transit Planning, Advances in Science, Technology \& Innovation, https://doi.org/10.1007/978-3-030-17308-1_33}

The original version of the book was inadvertently published with an incorrect figure 14 in Chapter "Mountains and Urbanism in Kandy", the figure 14 is updated with the correct figure listed below. The chapter and book have been updated with the changes. 


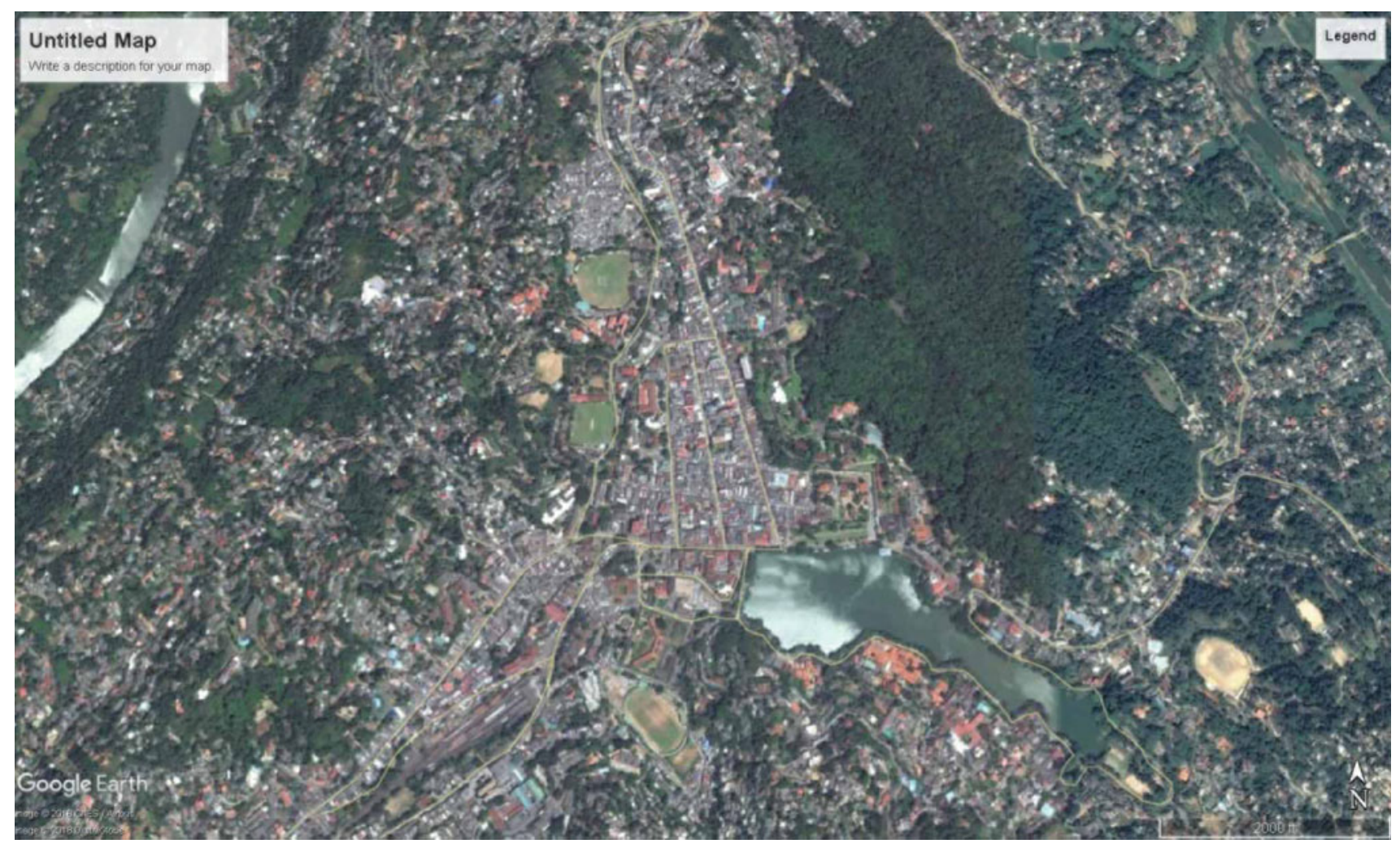

Fig. 14 Developments in Kandy and Udawatta kelle mountain forest 